\title{
EFEITO DO ESTÁDIO DE MATURAÇÃO DO FRUTO E DO TEMPO DE PRÉ-EMBEBIÇÃO DE ENDOCARPOS NA GERMINAÇÃO DE SEMENTES DE UMBUZEIRO (Spondias tuberosa Arr. Câm.) ${ }^{1}$
}

\author{
NIVÂNIA PEREIRA DA COSTA²; RISELANE DE LUCENA ALCÂNTARA BRUNO³; FRANCISCO XAVIER \\ DE SOUZA ${ }^{4}$ E ELIZA DOROTEA POZZOBOM DE A. LIMA ${ }^{3}$.
}

\begin{abstract}
RESUMO - O umbuzeiro é uma fruteira nativa do Nordeste brasileiro, cujos frutos são usados na alimentação humana, tendo, portanto, grande potencial de exploração agroindustrial. A lenta germinação das sementes limita a produção de mudas, daí a realização deste trabalho que objetivou estudar o efeito dos diferentes estádios de maturação do fruto e tempos de pré-embebição dos endocarpos em água na germinação das sementes de umbu. Os frutos foram despolpados manualmente, e os endocarpos pré-embebidos em água destilada substituída a cada 24 horas. Utilizou-se o delineamento experimental inteiramente ao acaso, em fatorial (4'4'2), sendo os fatores: estádios de maturação dos frutos (verde, de vez, maduro e maturação avançada), tempos de pré-embebição dos endocarpos em água ( $(0,48,96$ e 144 horas) e tipos de umbuzeiros (azedo e doce), com quatro repetições e dez endocarpos/parcela. Os endocarpos foram semeados em bandejas de isopor contendo Areia Quartzosa Distrófica. Pelos resultados, concluiu-se que o tipo de umbu e o estádio de maturação do fruto influenciaram na germinação. Entretanto, a pré-embebição dos endocarpos em água não influenciou na germinação das sementes de umbuzeiro.
\end{abstract}

Termos para indexação: Propagação, dormência, maturação de frutos, vigor.

\section{EFFECT OF THE FRUIT MATURATION STAGE AND THE ENDOCARP PREIMBIBITION TIME ON THE SEED GERMINATION OF UMBU TREE (Spondias tuberosa Arr. Câm.)}

\begin{abstract}
The umbu tree is a fruit crop of the Brazilian northeast, whose fruits are used in the human feeding, presenting therefore great potential of agroindustry exploration. The slow germination of the seeds limits the seedling production, justifying the accomplishment of this work, which objectifies to study the effect of different fruit maturation stages and water preimbibition times of the endocarps on the germination of the umbu seeds. The fruits were manually unpulped, the endocarps preimbibited in distilled water substituted each 24 hours. It was utilized the entirely randomized design, factorial $(4 \times 4 \times 2)$, being the factors: fruit maturation stages (green, semi-mature, mature and advanced maturation), water preimbibition times of the endocarps $(0,48,96$, and 144 hours) and types of umbu plants (sour and sweet), with 4 replicates and 10 endocarps.parcel $^{-1}$. The endocarps were sowed in expanded polyesthiren trays contends dystrophic quartzose sandy. From the results it is concluded that the type of umbu plant and the fruit maturation stage influenced the germination. However, the water preimbibition of the endocarps does not influenced the seed germination of the umbu tree.
\end{abstract}

Index terms: propagation, dormancy, fruit maturation, vigour.

O umbuzeiro é uma árvore frutífera nativa do semi-árido do Nordeste brasileiro (Duque, 1980), ainda explorada extrativamente. Os seus frutos são muito apreciados e procurados para o consumo in natura, sendo comercializados nos diversos mercados juntamente com produtos processados como polpa, doces, sucos e picolés. A espécie tem crescente importância socioeconômica para a região, fato confirmado pelo surgimento de várias pequenas agroindústrias de processamento.

No umbuzeiro, a propagação é feita normalmente por semente, que se encontra no interior do endocarpo, o qual é comumente chamado de "caroço". A germinação é lenta e desuniforme, constituindo-se em problema para a produção comercial de mudas, seja para plantio como pé-franco seja para uso como porta-enxerto. Isto deve-se ao tegumento da semente, estrutura crítica na dormência, que limita a entrada de água e oxigênio e impede, também, a expansão do embrião. Adriance \& Brison (1980) salientaram que a germinação de sementes pode ser acelerada por tratamentos de pré-embebição em água.

Outro fator de fundamental importância na germinação diz respeito à maturidade fisiológica da semente que, segundo Carvalho \& Nakagawa (2000), representa, teoricamente, o ponto em que a semente atinge o máximo de qualidade fisiológica, vigor,

1 (Trabalho 230/2000). Recebido: 16/10/2000. Aceito para publicação: 04/10/2001. Parte integrante da Dissertação de Mestrado do primeiro autor. 2 Enga. Agra., M.Sc. Rua Marrey Júnior, 75, Nova Jaboticabal, 14887-110. Jaboticabal, SP. npcosta@fcav.unesp.br.

3 D.Sc. Prof. Adj. da Universidade Federal da Paraíba, Campus III, 58397-000, Areia, PB.

3 Eng. Agr., M.Sc., Pesquisador da Embrapa Agroindústria Tropical. Fortaleza, CE. 
germinação, tamanho e peso de matéria seca.

Em virtude do grande potencial de exploração agroindustrial dessa fruteira, este trabalho teve como objetivo estudar o efeito de diferentes estádios de maturação do fruto e tempos de pré-embebição dos endocarpos em água, na germinação e vigor de plantas de umbuzeiro.

O ensaio foi conduzido em casa de vegetação, no Centro de Ciências Agrárias da Universidade Federal da Paraíba, no período de março a setembro de 1998. Antes da colheita, dez plantas de umbuzeiros vigorosas, sadias e com crescimento vegetativo normal foram selecionadas em função do tipo de fruto (azedo e doce), os quais foram colhidos, separados e os estádios de maturação (verde, de vez, maduros e maturação avançada) selecionados de acordo com o peso, comprimento, diâmetro (Tabela 1) e análise química (Acidez Total Titulável - ATT, expresso em gramas de ácido cítrico/100 $\mathrm{ml}$ de suco, realizada por titulometria, segundo metodologia do IAL (1973); $\mathrm{pH}$, realizado conforme metodologia do IAL (1973), utilizando-se de potenciômetro; Sólidos Solúveis Totais - SST, expresso em ${ }^{\circ}$ Brix, determinado por refratometria, conforme metodologia da AOAC (1970) e Ratio, determinado pelo quociente entre SST/ATT), como apresentados na Tabela 2. Os frutos dos estádios verdes, de vez e maduros foram colhidos diretamente das plantas, e os de maturação avançada, apanhados do chão, sob a copa dos umbuzeiros. $\mathrm{O}$ ensaio foi instalado no delineamento experimental inteiramente casualizado, em esquema fatorial ( $\left.4^{\prime} 4^{\prime} 2\right)$, sendo os fatores: estádios de maturação dos frutos (verde, de vez, maduro e maturação avançada), tempos de pré-embebição dos endocarpos em água $(0 ; 48 ; 96$ e 144 horas) e tipos de umbuzeiros (azedo e doce), com quatro repetições e dez endocarpos/parcela. Os frutos foram despolpados manualmente, os endocarpos préembebidos em água destilada por 0; 48; 96 e 144 h, com renovação da água a cada $24 \mathrm{~h}$. A semeadura foi realizada a $3 \mathrm{~cm}$ de profundidade, em bandejas de isopor de 72 células, contendo Areia Quartzosa Distrófica e irrigada de acordo com a necessidade. As avaliações foram feitas diariamente, por um período de 150 dias, para cálculo da percentagem de emergência de plântulas, e para a altura de planta e número de folhas e de folíolos; as avaliações foram realizadas aos 30 dias após a emergência.

\section{Emergência de plântulas}

A emergência de plântulas foi considerada baixa e irregular, uma vez que o início da emergência foi observado aos 16 dias após o semeio, e, aos 150 dias, a maior percentagem obtida foi de $56 \%$ em frutos doces, no estádio de vez (Tabela 3 ).

Analisando-se a influência do tipo de umbu na percentagem de emergência (Tabela 3), constatou-se, de maneira geral, que as sementes dos endocarpos do tipo doce apresentaram maior germinação nos diversos estádios de maturação. Para os endocarpos oriundos de frutos de vez, o tipo doce alcançou melhor desempenho $(48,41 \%)$ em relação aos do tipo azedo $(39,61 \%)$. Situação semelhante ocorreu para as sementes dos endocarpos provenientes de frutos maduros.

Observando-se o estádio de maturação do fruto sobre a percentagem de emergência de plântulas, constata-se, para o umbu azedo, que a maior percentagem de emergência foi das sementes provenientes de frutos de vez $(39,61 \%)$, seguido de maturação avançada $(37,41 \%)$ e verde $(35,32 \%)$. De maneira geral, os resultados encontrados refletem a desuniformidade de germinação das sementes de umbu do tipo azedo, provavelmente devido à grande variabilidade genética das plantas matrizes. Por outro lado, percebe-se, dentre os demais estádios de maturação, que as sementes dos endocarpos de frutos maduros apresentaram menor percentagem de emergência. Isto ocorreu, provavelmente, em virtude de o endocarpo possuir as camadas externa e interna denso-fibrosa (lignificada) totalmente desenvolvidas, dificultando a expansão do embrião, o que talvez não tenha ocorrido nos endocarpos dos frutos verde e de vez.

Nas sementes do tipo doce, não houve diferença significativa para a emergência de plantas nos estádios de vez $(48,41 \%)$, maturação avançada $(43,48 \%)$ e maduros $(39,97 \%)$. A menor percentagem de emergência foi obtida nas sementes procedentes de frutos verdes; isto se deve, certamente, à incompleta maturação fisiológica da semente. Para as demais sementes, cujas percentagens de emergência não diferiram estatisticamente entre si, os dados alcançados refletem o proposto por Carvalho \& Nakagawa (2000).

Ao analisar os diferentes tempos de pré-embebição dos endocarpos em água, constata-se que não houve diferença significativa entre os tempos de pré-embebição estudados nos endocarpos do tipo azedo (Tabela 4). Entretanto, em valores absolutos, a melhor percentagem de emergência ocorreu nas sementes dos endocarpos pré-embebidos por $48 \mathrm{~h}$, confirmando mais uma vez a possibilidade de o endocarpo, neste estádio, encontrar-se menos lignificado e a semente, provavelmente, com bom desenvolvimento fisiológico, não ocorrendo o mesmo com endocarpos de frutos maduros e maturação avançada devido à dificuldade de penetração de água pela terceira camada (que está em contato com a semente) por ser lignificada e não apresentar perfurações.

Nas sementes dos endocarpos do tipo doce, houve uma diminuição na percentagem de emergência com o aumento do tempo de pré-embebição em água. A pré-embebição, a partir de 96h, reduziu significativamente a emergência de plântulas. Entretanto, em valores absolutos, o tipo doce apresentou maior desempenho germinativo quando comparado ao tipo azedo nos tempos de imersão estudados.

\section{Altura de planta}

As plantas oriundas de endocarpos do tipo azedo apresentaram altura de $11,77 \mathrm{~cm}$, seguido do tipo doce com $12,27 \mathrm{~cm}$, não diferindo estatisticamente entre si (Tabela 5).

Com relação ao estádio de maturação do fruto, constata-se que plantas originadas das sementes de endocarpos em maturação avançada $(12,55 \mathrm{~cm})$ e maduros $(12,53 \mathrm{~cm})$ alcançaram maior desempenho (altura), seguido do estádio de vez $(11,87 \mathrm{~cm})$, sendo que este não diferiu de frutos verdes que alcançaram menor crescimento em altura. Isso é explicado por Delouche (1975), quando afirma que sementes originadas de frutos imaturos alcançam a capacidade germinativa; entretanto, as plântulas obtidas dessas sementes apresentam baixo vigor.

Considerando-se os diferentes tempos de préembebição de endocarpos em água, não houve diferença significativa para o crescimento em altura de plantas.

\section{Número médio de folhas/planta}

Pelos dados da Tabela 5, constata-se que não houve diferença estatística entre os fatores tipo de umbu, estádio de maturação de fruto e tempo de pré-embebição em água dos endocarpos. A média foi de 5 folhas/planta de umbuzeiro aos 30 
TABELA 1 - Dados médios de caracterização física oriundos de 40 frutos de umbuzeiros azedos e doces, em cada estádio de maturação. Areia-PB. 1998.

\begin{tabular}{|c|c|c|c|}
\hline Tratamentos & $\begin{array}{cc}\text { P eso d o fruto } \\
(\mathrm{g})\end{array}$ & $\begin{array}{c}\text { D iâ m e tro } \\
(\mathrm{m} \text { m })\end{array}$ & $\begin{array}{c}\text { Comprim ento } \\
(\mathrm{m} \mathrm{m})\end{array}$ \\
\hline A z e do & $13,47 \mathrm{~b}$ & $26,13 \mathrm{~b}$ & 32,16 a \\
\hline $\mathrm{C} \mathrm{V}(\%)$ & 13,13 & 4,95 & 4,30 \\
\hline D M S Coluna & 1,38 & 0,98 & 1,02 \\
\hline \multicolumn{4}{|c|}{ Estádios de maturaçãodo fruto } \\
\hline M aduro & $16,31 \mathrm{a}$ & 28,94 a & 32,80 a \\
\hline M a turação ava nçad a & $13,96 \mathrm{ab}$ & $26,35 \mathrm{~b}$ & 31,79 a \\
\hline $\mathrm{CV}(\%)$ & 13,13 & 4,95 & 4,30 \\
\hline D M S Coluna & 2,60 & 1,85 & 1,92 \\
\hline
\end{tabular}

Médias seguidas de mesma letra na coluna não diferem significativamente entre si, pelo teste de Tukey, a 5\% de probabilidade.

TABELA 2 - Médias dos resultados da análise química de 40 frutos de umbuzeiros azedos e doces, em cada estádio de maturação. Areia-PB. 1998.

\begin{tabular}{|c|c|c|c|c|}
\hline \multirow[t]{2}{*}{ Tipos de frutos e estádios de maturação } & \multicolumn{4}{|c|}{ Variáveis analisadas } \\
\hline & A T T (\% ácido cítrico) & $\mathrm{pH}$ & S S T $\left({ }^{\circ}\right.$ brix $)$ & $\mathrm{S} \mathrm{S} \mathrm{T/A} \mathrm{T} \mathrm{T}$ \\
\hline Azedo-Verde & 2,64 & 2,10 & 7,00 & 2,65 \\
\hline Azedo-Maduro & 1,56 & 2,26 & 9,50 & 6,11 \\
\hline Azedo - M aturação avançada & 1,01 & 2,26 & 10,0 & 9,90 \\
\hline Doce - Maduro & 1,49 & 2,28 & 10,10 & 6,86 \\
\hline Doce - M aturação avançada & 1,56 & 2,27 & 10,0 & 6,28 \\
\hline
\end{tabular}

TABELA 3 - Germinação de sementes de umbuzeiro dos tipos azedo e doce oriundas de frutos de diferentes estádios de maturação. Areia-PB. 1998.

\begin{tabular}{|c|c|c|c|c|c|c|c|c|}
\hline \multirow[t]{2}{*}{$\begin{array}{l}\text { Tipos de } \\
\text { umbu }\end{array}$} & \multicolumn{4}{|c|}{ Estádios de maturação dos frutos (Dados } & \multicolumn{4}{|c|}{$\begin{array}{l}\text { Estádios de maturação dos frutos } \\
\text { (Dados originais em \%) }\end{array}$} \\
\hline & verde & de vez & maduro & mat. avançada & verde & de vez & maduro & mat. avançada \\
\hline azedo & $35,32 \mathrm{ABa}$ & $39,61 \mathrm{Ab}$ & $29,54 \mathrm{Bb}$ & $37,41 \mathrm{ABa}$ & 34,0 & 41,0 & 25,0 & 39,0 \\
\hline doce & $33,39 \mathrm{Ba}$ & $48,41 \mathrm{Aa}$ & $39,97 \mathrm{ABa}$ & $43,48 \mathrm{Aa}$ & 31,0 & 56,0 & 42,0 & 48,0 \\
\hline
\end{tabular}

$\mathrm{CV}(\%)=23,75$

DMS Linha $=8,44$

DMS Coluna $=6,40$

Médias seguidas das mesmas letras maiúsculas nas linhas e minúsculas nas colunas não diferem entre si, pelo teste de Tukey, ao nível de $5 \%$ de probabilidade.

TABELA 4 - Germinação de sementes de umbuzeiro dos tipos azedo e doce sob diversos tempos de pré-embebição em água. Areia-PB. 1998.

\begin{tabular}{|c|c|c|c|c|c|c|c|c|}
\hline \multirow[t]{2}{*}{ Tipo de umbu } & & \multicolumn{3}{|c|}{ Tempos de pré-embebição (h) } & \multicolumn{4}{|c|}{$\begin{array}{l}\text { Tempos de pré-embebição (h) } \\
\text { (Dados originais em \%) }\end{array}$} \\
\hline & 0 & 48 & 96 & 144 & 0 & 48 & 96 & 144 \\
\hline Azedo & $34,76 \mathrm{Ab}$ & $40,87 \mathrm{Aa}$ & $33,80 \mathrm{Aa}$ & $32,45 \mathrm{Aa}$ & 34,0 & 43,0 & 32,0 & 29,0 \\
\hline Doce & $48,37 \mathrm{Aa}$ & $43,09 \mathrm{ABa}$ & $35,73 \mathrm{Ba}$ & $38,08 \mathrm{Ba}$ & 56,0 & 47,0 & 35,0 & 39,0 \\
\hline
\end{tabular}

$\mathrm{CV}(\%)=23,75$

DMS Linha $=8,44$

DMS Coluna $=6,40$

Médias seguidas das mesmas letras maiúsculas nas linhas e minúsculas nas colunas não diferem significativamente entre si, pelo teste de Tukey, ao nível de $5 \%$ de probabilidade. 
TABELA 5 - Médias de altura de planta e número de folhas por planta de umbuzeiro. Areia-PB. 1998.

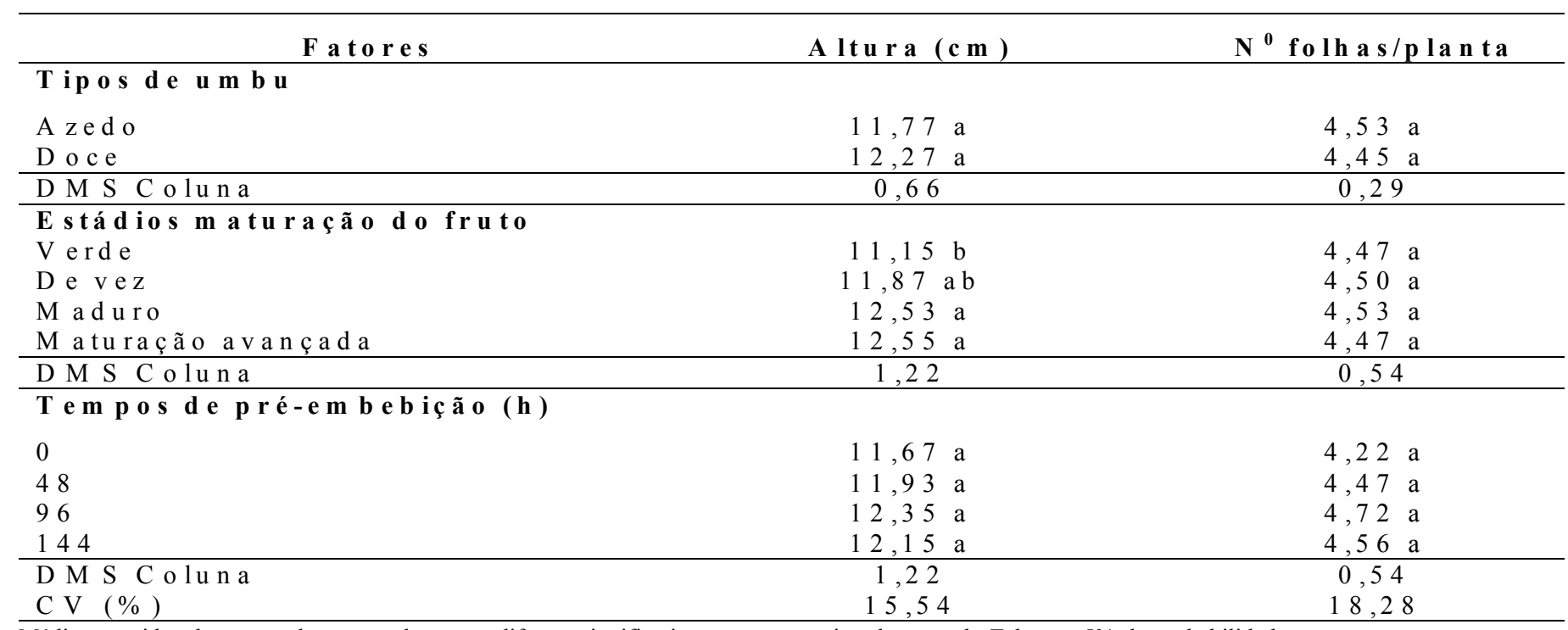

Médias seguidas de mesma letra na coluna não diferem significativamente entre si, pelo teste de Tukey, a $5 \%$ de probabilidade.

dias após a emergência.

Conclui-se que o tipo de umbu e o estádio de maturação do fruto influenciaram na germinação e altura de plantas; as maiores percentagens de germinação foram obtidas nas sementes dos endocarpos dos frutos de vez e em maturação avançada; os diferentes tempos de pré-embebição dos endocarpos em água não influenciaram na germinação das sementes de umbuzeiro.

\section{REFERÊNCIAS BIBLIOGRÁFICAS}

ADRIANCE, G.W.; BRISON, F.R. Propagation of Horticultural Plants. 2 ed. Bombay Tata: McGraw-Hill, 1980. 289p.

ASSOCIATION OF OFFICIAL ANALYTICAL CHEMISTRY. Official methods of analisys of the association of official analytical chemistry. Washington, 1970.1015p.

CARVALHO, N.M.; NAKAGAWA, J. Sementes: ciência, tecnologia e produção. Jaboticabal: FUNEP, 2000. 588p. Ilustrado.

DELOUCHE, J.C. Recentes conquistas de pesquisas tecnológicas de sementes. In: DELOUCHE, J.C. Pesquisa em Sementes no Brasil. Brasília: AGIPLAN, 1975. p.27-36.

DUQUE, G. O umbuzeiro. In: O Nordeste e as lavouras xerófilas. 3. ed. Mossoró: ESAM / Fundação Guimarães Duque, 1980. p. 283-89. (Coleção Mossoroense - 143).

INSTITUTO ADOLFO LUTZ. Normas analíticas, métodos químicos e físicos para análise de alimentos. São Paulo: Instituto Adolfo Lutz, 1973. v.1, 371p. 